\title{
O QUE É “ONTOLOGIA DO PRESENTE”?'
}

\author{
Helton Adverse ${ }^{\star}$ \\ Universidade Federal de Minas Gerais
}

\begin{abstract}
This paper's aim is to elucidate the meaning of the paradoxical expression "ontology of the present", utilized by Foucault in his latest works. To achieve this goal, I adopted a twofold strategy: on the one hand, it was useful to recall that this was not the first time Foucault used a deranging expression. In the 1960's, in the period he developed his "archeology of knowledge", we can find in some of his major works the husserlian term "historical a priori". On the other hand, I had to analyze some aspects of his interpretation of the modernity that we can find in his last articles, interviews and lessons in the Collège de France. In these occasions, Kant's philosophy was the main theoretical influence.
\end{abstract}

KEYWORDS: Foucault; historical a priori; ontology of the present; modernity; Kant.

oucault utiliza termo "ontologia do presente" para definir, no final de sua vida, a natureza de seu trabalho filosófico. Se quisermos apreender o sentido de sua pesquisa, parece bastante razoável investigar o significado dessa expressão, em que pese à sua estranheza evidente mesmo a leitor pouco atento. Com efeito, uma "ontologia do presente"

^heltonadverse@hotmail.com

${ }^{1}$ Este artigo resulta de uma comunicação proferida por ocasião da Jornada Foucault, realizada na FALE-UFMG em setembro de 2010. Mantive a forma da exposição oral. Gostaria de registrar meus agradecimentos aos organizadores do evento e, em especial, a meu colega Antônio Orlando Dourado-Lopes. As traduções, quando não há menção contrária, são minhas. 
soa como um oxímoro, como uma contradição na qual o segundo termo aparentemente arruína o primeiro, retirando-lhe toda a força que a tradição do pensamento filosófico lhe incutiu. Ou pode bem ser o contrário, isto é, a "ontologia" pode exercer um efeito nefasto sobre o "presente", petrificando-o na dimensão fria da eternidade incompatível com seu dinamismo e calor próprios, mergulhando-o no nada indiferenciado do nunc stans.

Não estou seguro, porém, de que a intenção primeira de Foucault, ao se servir de expressão tão insólita, fosse produzir qualquer choque em seu leitor ou ouvinte, visto que a expressão foi utilizada pela primeira vez na aula de 5 de janeiro de 1983 do curso Le gouvernement de soi et des autres, realizado no Collège de France. ${ }^{2}$ Antes, acredito que seu objetivo fosse o de explorar a tensão que resulta da associação entre os termos, um deles conservando o poder totalizador dos universais e o outro resistindo a seu domínio na afirmação intransigente do valor da singularidade. $O$ primeiro passo que gostaria de dar, na tentativa de elucidação da expressão "ontologia do presente", é chamar a atenção para a existência desse conflito "semântico" em seu interior. Um conflito, contudo, que é a fonte de sua força hermenêutica e que confere ao discurso filosófico da modernidade a capacidade de dizer algo significativo a respeito de quem nós somos na atualidade (mais adiante, voltarei a esse assunto). Por enquanto, no intuito de esmiuçar o significado da expressão, valeria a pena lembrar que não é a primeira vez que Foucault se serve de uma expressão contraditória. Em trabalhos dos anos 1960, e especialmente em As palavras e as coisas, a noção de a priori histórico ocupa um lugar central nas análises que constituem sua arqueologia das ciências humanas.

A noção de a priori histórico, como já foi observado por alguns comentadores $^{3}$ (e alusivamente pelo próprio Foucault), ${ }^{4}$ é de origem husserliana. Em seu texto sobre a origem da geometria, Husserl recorre a ela para compreender o processo de formalização de uma ciência como a geometria e ao mesmo tempo a possibilidade de essa ciência ser pensável

${ }^{2}$ Cf. Foucault, M. Le gouvernement de soi et des autres. Paris: Gallimard/Seuil, 2008, p. 22.

${ }^{3}$ Cf. Lebrun, G. Note sur la phénoménologie dans "Les mots el les choses". In: Canguilhem, G. (Org.). Michel Foucault philosophe. Paris: Seuil, 1989. Cf. também Han, B. L'ontologie manquée de Michel Foucault. Grenoble: Millon, 1998, p. 110-111.

${ }^{4}$ Cf. Foucault, M. La vie: l'expérience et la science. In: Dits et écrits $I V$. Paris: Gallimard, 1994e, p. 772. Mas em uma entrevista de 1969, a referência a Husserl é clara (Entretien avec Michel Foucault. In: . Dits et écrits II. Paris: Gallimard, 1994a, p. 165-166). 
por um indivíduo capaz de ter dela uma intuição apodítica apreendendoa em todos os seus aspectos, isto é, em sua "objetidade ideal". ${ }^{5}$ Não sendo esse o problema de Foucault, mas sim trazer à luz as condições de possibilidade que asseguram a conformação de certos saberes em determinados momentos, sua concepção de a priori histórico visa a enfrentar uma série de questões estranhas à fenomenologia. É o conceito de epistéme - entendido como "o conjunto das relações que podem unir, em uma dada época, as práticas discursivas que dão lugar a figuras epistemológicas, a ciências, eventualmente a sistemas formalizados" ${ }^{6}$ que lhe dá pleno sentido e delimita o âmbito de sua aplicabilidade. As noções de "origem", de "idealidade" e de "ato criador", tão caras à fenomenologia husserliana, são abandonadas em favor de uma concepção histórica do conhecimento na qual a figura do sujeito criador, doador de sentido é elidida. De acordo com o projeto de uma arqueologia do saber, a interrogação de Husserl sobre como "a idealidade geométrica atinge a objetividade ideal a partir de seu surgimento originário intrapessoal no qual ela se apresenta como formação no espaço de consciência na alma do primeiro inventor?"” é desprovida de qualquer propósito. Mas apesar dessas diferenças não negligenciáveis, há um elemento comum que, ao ser integrado em projetos filosóficos muito distintos, termina por se tornar quase irreconhecível. Refiro-me ao enfrentamento entre a universalidade e a singularidade que Husserl resolve na idealidade objetiva formalizada por meio da linguagem (a qual permite a mediação entre a consciência individual e a objetividade) e que Foucault assume na forma da relação entre descontinuidade e continuidade epistêmicas. Dizendo de outro modo, se, no âmbito de uma arqueologia do saber, o desaparecimento do sujeito transcendental tornava caduca a questão da mediação entre o universal e o singular, ela parece retornar à vida no reconhecimento de que a pura descontinuidade é impossível. A pura descontinuidade termina por suprimir a dimensão histórica. Como esse não é o lugar para apresentar as provas desse reconhecimento, faço apenas observar que Foucault jamais afirmou que as rupturas, as passagens de uma configuração histórica do conhecimento à outra, são incompatíveis com a permanência de alguns elementos que são, sem dúvida, profundamente

\footnotetext{
${ }^{5}$ Cf. Husserl, E. Lorigine de la géométrie. Trad. J. Derrida. In: La crise des sciences européennes et la phénoménologie transcendentale. Trad. G. Granel. Paris: Gallimard, 1976, p. 403-427.

${ }^{6}$ Cf. Foucault, M. L'archéologie du savoir. Paris: Gallimard, p. 250.

${ }^{7}$ Cf. Husserl, op. cit., p. 407.
} 
remanejados, mas cuja presença tênue é imprescindível para o projeto arqueológico. A título de exemplo, vale lembrar que As palavras e as coisas tomam como seu problema próprio investigar o modo pelo qual a vida, o trabalho e a linguagem foram pensados em diversas epistémai.

Acredito, porém, que possamos extrair um segundo benefício dessa aproximação de Foucault a Husserl. E isso irá nos permitir retornar ao contexto em que Foucault emprega a expressão "ontologia do presente". No começo de sua investigação sobre a origem da geometria, Husserl afirma o seguinte:

No curso de nossas meditações históricas sobre a filosofia moderna, pela primeira vez, aqui, com Galileu, graças ao desvelamento dos problemas de fundo concernentes à origem de sentido da geometria e, sobre esse fundamento, da origem do sentido de sua nova física, o esplendor de uma luz brilha sobre nosso empreendimento: a vontade de realizar, sob a forma de meditações históricas, tomadas de consciência de nossa própria situação filosófica presente, e isso na esperança de que, finalmente, nós poderemos por isso tomar posse do sentido, do método e do começo da filosofia, daquela filosofia à qual nossa vida quer e deve se consagrar. ${ }^{8}$

Certamente a "empresa" foucaultiana tem objetivos muito diferentes da de Husserl (e mesmo suas visões acerca da filosofia e da ciência modernas são discrepantes), mas o que eu gostaria de destacar é que ambas são animadas por esse mesmo espírito de "atualidade", ambas são marcadas pelo mesmo desejo de lançar luz sobre nossa situação filosófica presente tomando como expediente as análises históricas. $\mathrm{Na}$ linguagem do Foucault da segunda metade dos anos 1960, essa vontade encontrava vazão sob a forma de um "diagnóstico do presente", uma espécie de "atividade filosófica" que ele colocava então sob os auspícios de Nietzsche em uma entrevista de 1967:

Eu busco diagnosticar, realizar um diagnóstico do presente: dizer o que nós somos hoje e o que significa, hoje, dizer o que dizemos. Esse trabalho de escavação sob nossos pés caracteriza desde Nietzsche o pensamento contemporâneo e, nesse sentido, posso me declarar filósofo. ${ }^{9}$

\footnotetext{
${ }^{8}$ Cf. Husserl, op. cit., p. 403-404.

${ }^{9}$ Entrevista a P. Caruso publicada originariamente em La fiera letteraria, n. 39 (setembro de 1967) e reeditada em Dits et écrits I (p. 601-620; a citação encontra-se na p. 606).
} 
É bem verdade que essa concepção de filosofia como diagnóstico implica o abandono da "perspectiva totalizadora" que, segundo Foucault, parece caracterizar certo modo de se fazer filosofia, especialmente aquele vinculado a Hegel. No momento polêmico em que essa entrevista é concedida, Foucault marca suas diferenças com a tradição dialética e a ela associa a fenomenologia husserliana: a ideia de uma filosofia que visa apenas à totalidade, diz ele, está em vias de se extinguir; a filosofia hoje é muito mais uma forma de atividade que se pode exercer em campos diferentes. Assim, por exemplo, Bertrand Russell teria, segundo Foucault, realizado uma atividade filosófica quando, no campo da lógica, "esclareceu a dificuldade, a impossibilidade de considerar a 'existência' como um atributo, ou a proposição existencial como uma proposição de tipo sujeito-atributo". A filosofia deixa de ser um discurso sobre a totalidade e passa a ser "um tipo de atividade interna a um domínio objetivo". E, na medida em que Husserl buscou "repensar o conjunto de nosso universo de conhecimentos em função e em relação com um sujeito transcendental", ele seria o último filósofo com pretensões "absolutamente universalistas". 10

Ora, sabemos que essa não será a última palavra de Foucault a respeito de Husserl. Ele encontrará, a partir do final dos anos 1970, traços de continuidade entre o seu pensamento e o do pensador alemão, e precisamente nas ocasiões em que Foucault examina a natureza da atividade crítica que caracteriza a filosofia contemporânea. No mínimo dois textos podem ser aqui evocados: a conferência pronunciada em 1978 na Sociedade Francesa de Filosofia e a introdução, do mesmo ano, à edição americana do livro de $\mathrm{G}$. Canguilhem ( $O$ normal e o patológico). Em ambos os textos, porém, as afinidades com Husserl se devem à matriz kantiana à qual podem se filiar suas filosofias. É a essa matriz comum, portanto, que devemos dirigir nossa atenção se quisermos apreender o sentido de uma "ontologia do presente".

A referência maior dessa ontologia é um texto que Kant publica em 1783 (ou 1784), "Resposta à Pergunta: O Que é Esclarecimento?" e que Foucault comenta em diversas ocasiões, inclusive nos dois textos mencionados acima. $\mathrm{O}$ grande interesse desse pequeno artigo se deve ao fato de ser colocada na agenda filosófica a questão da atualidade, ou melhor, a atualidade como questão.

${ }^{10}$ Cf. Foucault, M. Qui êtes-vous, Professeur Foucault? In: Dits et écrits $I$. Paris: Gallimard, 1994f, p. 612. 
Depois de Kant, diz Foucault, o trabalho filosófico (incluindo aí sua própria investigação) é antes de tudo crítico, e com isso se quer significar que a modernidade filosófica é a idade da crítica. Certamente, essa proposição ecoa a conhecida passagem do primeiro prefácio da Crítica da razão pura em que Kant escreve que "nossa época é a época da crítica à qual tudo tem de se submeter". Porém, o interesse de Foucault é mostrar que a crítica é a condição de possibilidade da filosofia na modernidade. Nesse sentido, a filosofia de Kant estabelece o horizonte no qual irá se constituir o pensamento filosófico moderno. Mas convém notar que a herança kantiana é, para Foucault, muito mais complexa do que simplesmente a imposição de uma ordem do dia filosófica. Por isso, Was ist Aufklärung? é um texto importante, uma vez que situa de modo preciso o lugar onde deve ser articulado o pensamento filosófico na modernidade. Assim, na aula de 5 de janeiro de 1983, Foucault afirma que a filosofia, a partir do artigo de Kant, se torna "a superfície de emergência de sua própria atualidade discursiva, atualidade que ela interroga como evento, como um evento do qual ela tem de dizer o sentido, o valor, a singularidade filosófica, e no qual ela tem de encontrar ao mesmo tempo sua própria razão de ser e o fundamento do que ela diz". ${ }^{11}$

Essa declaração é fundamental. Em primeiro lugar, ela permite ver o posicionamento vertical do pensamento filosófico com relação a si mesmo e com relação ao tempo histórico em que ele é projetado. Por outro lado, podemos adivinhar também que este redobramento caracteriza a reflexão do próprio Foucault, herdeiro que realiza uma leitura sagital de sua própria filosofia a partir da filosofia de Kant. ${ }^{12}$ Isso significa que a Aufklärung talvez possa ser compreendida como um dispositivo que simultaneamente estrutura o pensamento filosófico e é por ele acionado. Nesse sentido, a Aufklärung é menos um momento histórico do que uma atitude filosófica ou, para ser mais preciso, ela constitui, na história do pensamento, a ocasião privilegiada em que a filosofia pode compreender a si mesma como um éthos.

Para entender melhor esses pontos, façamos uma rápida passagem pelo texto de Kant.

\footnotetext{
${ }^{11}$ Cf. Foucault, op. cit., 2008, p. 14.

${ }^{12}$ Ponto de vista semelhante é defendido por Jorge Dávila em Una exégesis del texto ¿Quées la Ilustración? como testamento intelectual de M. Foucault. Literatura y conocimiento. Michel Foucault. Caracas, Ediciones de la ULA, 1999 (acessível em < http:/ /www.saber.ula.ve/bitstream/123456789/15900/1/davila-ilustracion.pdf >).
} 
O que leva Kant a inquirir a natureza do Esclarecimento? Foucault observa, deixando de lado os detalhes, que a ocasião foi assegurada por uma publicação periódica, a Berlinische Monatsschrift, que havia iniciado um debate precisamente sobre essa questão. Contudo, talvez valha a pena reconstituir o contexto em que o artigo se originou para apreendermos os elementos que estão em jogo seja na visão kantiana do Esclarecimento seja na interpretação de Foucault. Para isso vou lançar mão do estilo inimitável de Rubens Rodrigues Torres Filho:

O ponto de partida (...) foi a questão do casamento civil. Johan Erich Biester, um dos fundadores do Mensário Berlinense, publicação do círculo de intelectuais que se autodenominava "Sociedade dos Amigos da Ilustração" ou "Sociedade das Quartas-Feiras", por causa das reuniões semanais que mantinham visando desenvolver e propagar a liberdade de crítica e de pensamento, publicava em 1783, nesse periódico, sob o pseudônimo de E.v.K., seu artigo: "Proposta de não mais se dar trabalho aos eclesiásticos na consumação do matrimônio". Argumentando que outras relações jurídicas entre seres humanos, de igual dignidade e importância, dispensavam qualquer sanção religiosa, defendia o mesmo tratamento para o contrato que liga homem e mulher, rematando com a frase: "Afinal, para ilustrados são desnecessárias todas essas cerimônias!” (...) A resposta não demora. Outro daqueles mesmos "amigos da Ilustração", Johan Friedrich Zöllner, é de opinião contrária. Nada mais natural. Estamos na época das luzes e do debate livre, e o Mensário Berlinense irá publicar no número seguinte sua resposta, sob o título: "Será aconselhável não mais sancionar o vínculo matrimonial pela religião?”. Seu argumento, quanto ao assunto mesmo da discussão, também não tem nada de extraordinário: o casamento é um ato que decide, em grande medida, sobre a felicidade do ser humano, e não se deve tratar todas as obrigações jurídicas como se fossem do mesmo grau. O importante, porém, quanto à mudança de atitude, já está inscrito no tom do título: Ist es ratsam... (Será recomendável...). Não é prudente, diz o texto, desvalorizar a religião em todos os assuntos profanos e desse modo, "sob o nome de Ilustração, confundir as cabeças e os corações dos homens". Ilustrar, sim: o espírito do tempo e o bem da humanidade o exigem. Mas fazer da Ilustração, tomada sem crítica e sem a consciência de seus limites, um pretexto para a subversão e para a anarquia - ilustrar às cegas - seria pôr a perder até mesmo aquilo que as Luzes conseguiram, até agora, laboriosamente, conquistar. E será nesse ponto, com esse contexto preciso, que Zöllner se tornará o formulador da pergunta clássica, que atinge em seu nervo mais profundo a consciência do ilustrador: "O que é Ilustração?”. E o autor comenta: "Essa pergunta, que é quase tão importante quanto: $\mathrm{O}$ 
que é a verdade, deveria certamente ser respondida antes que se comece a ilustrar! E eu ainda não a encontrei respondida em parte nenhuma!". ${ }^{13}$

Como podemos ver, a motivação primeira que leva o mensário a estabelecer o debate público acerca do Esclarecimento é a suspeita de que ele representa um perigo para as instituições sociais e políticas. Isso porque ele parece colocar em questão o princípio de autoridade, fundamental tanto em matéria religiosa quanto em matéria política. $\mathrm{O}$ artigo de Kant terá como alvo mais próximo dissipar essa desconfiança mostrando que a Aufklärung não representa uma verdadeira ameaça à ordem; pelo contrário. Kant adotará a seguinte estratégia: apresentar de início uma definição transcendental da Aufklärung ${ }^{14}$ para em seguida examinar as condições de possibilidade de sua efetivação na realidade empírica. A definição é formulada nos seguintes termos:

Esclarecimento é a saída (Ausgang) do homem de sua menoridade da qual ele próprio é culpado. A menoridade é a incapacidade de fazer uso de seu entendimento sem a direção de outro indivíduo. O homem é o próprio culpado dessa menoridade se a causa dela não se encontra na falta de entendimento, mas na falta de decisão e coragem de servirse de si mesmo sem a direção de outrem. Sapere aude! Tem coragem de fazer uso de seu próprio entendimento, tal é o lema (Wahlspruch) de seu próprio entendimento. ${ }^{15}$

Em sua definição transcendental, o Esclarecimento corresponde a um uso perfeito do próprio entendimento no qual é confirmada a autonomia do homem. Kant vai salientar que a perda de tal autonomia é de responsabilidade do próprio homem, uma vez que a natureza não impõe quaisquer obstáculos a seu exercício (na verdade, a filosofia da história, presente nas entrelinhas desse artigo, afirma que a natureza depositou em nós os "germes" que, quando desenvolvidos, nos conduzirão

\footnotetext{
${ }^{13}$ Cf. Torres Filho, R. R. Respondendo à pergunta: quem é a Ilustração?. In: Ensaios defilosofia ilustrada. São Paulo: Brasiliense, 1987, p. 87-88. Para uma pormenorizada contextualização filosófica desse debate, é imprescindível a consulta ao livro organizado por James Schmidt, What is Enlightenment? Eighteenth-Century answers and Twentieth-Century questions. Berkeley: University of California Press, 1996.

${ }^{14}$ Esta é a sugestão de leitura de Torres Filho, a qual me parece inteiramente acertada.

${ }^{15}$ Cf. Kant, I. Resposta à pergunta: "que é Esclarecimento?” (Aufklärung). Trad. Floriano de S. Fernandes. In: .Immanuel Kant. Textos seletos. Petrópolis: Vozes, 1985, p. 100-101 (grifos de Kant).
} 
à maioridade). Em que consiste essa autonomia é explicitado no parágrafo seguinte a partir do contraste com a situação de menoridade: "É tão cômodo ser menor. Se tenho um livro que faz as vezes de meu entendimento, um diretor espiritual que por mim tem consciência, um médico que por mim decide a respeito de minha dieta, etc., então não preciso de esforçar-me eu mesmo". ${ }^{16}$

Foucault não deixa de observar que nos deparamos aqui com os registros em que operam as três críticas, isto é, o teórico, o prático e o estético, o que torna visível a linha de continuidade entre esse artigo e a reflexão sistematizada que encontramos no projeto crítico. É necessário compreender qual a natureza desse vínculo. Há pouco, me referi ao princípio de autoridade e à definição transcendental. Vou tentar articular esses dois pontos com a esperança de explicitar essa questão.

O que parece assustar Zöllner é a possibilidade de a ideia de Esclarecimento estar a serviço da desordem e colocar em xeque os pressupostos da vida social. A apresentar uma definição não empírica de Esclarecimento, Kant apazigua os medos de Zöllner porque desloca o campo em que o assunto tem de ser tratado: a Aufklärung é, essencialmente, o uso livre de nossa faculdade intelectiva e não deve ser identificada, sem mais, com a liberdade social. Para evidenciar essa diferença, Kant estabelece no coração de seu texto a distinção entre uso público e uso privado da razão. No primeiro está em questão o uso da razão que fazemos como sábios (Gelehrter) "diante do grande público do mundo letrado (Leserwelt)" ${ }^{17} \mathrm{O}$ uso privado corresponde àquele que "o sábio pode fazer de sua razão em um certo cargo público (bürgenlichen Posten) ou função a ele confiado". ${ }^{18}$

O Esclarecimento concerne à liberdade de uso público da razão, isto é, àquele que está, em princípio, desconectado da ordem social. A liberdade nesse domínio (no "mundo letrado") é, diz Kant, "a mais inofensiva entre tudo aquilo que se possa chamar liberdade". ${ }^{19} \mathrm{Em}$ contrapartida, a liberdade de uso privado pode ser muito severamente limitada sem impedir o progresso em direção ao Esclarecimento. Mas o que significa essa limitação do uso privado da razão? Significa, antes de tudo, a obediência às "incumbências estranhas" (fremde Auftage) que

\footnotetext{
${ }^{16}$ Cf. Kant, op. cit., p. 100-103.

${ }^{17}$ Cf. Kant, op. cit., p. 104-105 (grifo de Kant).

${ }^{18}$ Cf. Kant, op. cit., p. 104-105.

${ }^{19}$ Cf. Kant, op. cit.
} 
são inerentes a toda função ou cargo. No uso privado de sua razão, o homem é tomado como "funcionário", como parte de uma máquina cujo funcionamento é necessário para o bem-estar dos membros de uma comunidade. Esta obediência às regras é incompatível com a livre atividade de raciocínio. No que concerne ao uso público, está precisamente em jogo a liberdade de raciocínio. Mas como se trata de registros diferentes de uso da razão, a plena liberdade de raciocínio não pode resultar em prejuízo para a sociedade. Dito de outra maneira, o que preocupa a Kant é precisamente a confusão entre público e privado, ou ainda, como observa Foucault, a sobreposição do princípio da obediência ao uso público da razão. ${ }^{20}$

Essa sobreposição é correlata à ausência de raciocínio ou, para reatarmos com a definição transcendental do Esclarecimento, ela é correlata à perda de autonomia. A realidade histórica sobre a qual Kant lança seu olhar crítico é aquela na qual os homens estão impedidos de raciocinar e obrigados a obedecer (a exceção é a Prússia pois nela um senhor diz "Raciocinai, tanto quanto quiserdes, e sobre o que quiserdes, mas obedecei!"). ${ }^{21}$ O que gostaria de ressaltar é a introdução, nesse ponto, de uma tensão que parece estruturar a argumentação do resto do artigo. Com efeito, a exigência de obediência, longe de ser contestada por Kant, reintroduz o princípio de autoridade (à primeira vista antagônico à noção de Esclarecimento). Mas o insere em uma outra dimensão que permite compreender a coerência do texto. O princípio de autoridade é inscrito na esfera da legalidade. ${ }^{22}$ Kant está, ao mesmo tempo, reconhecendo a necessidade de obedecer às leis e regras que organizam o corpo social e afirmando o direito de existência de um espaço no qual o livre embate das ideias possa ser efetuado. Este espaço não é ameaça à legalidade. Pelo contrário: a convicção de Kant (e por esse meio ele pode tranquilizar a Zöllner e aos homens de poder) é a de que a Aufklärung, quando alcançada, se identifica com o respeito às leis. Os fundamentos dessa identificação são explicitados em sua filosofia do direito, na qual autonomia prática encontra uma de suas expressões na elaboração de uma constituição republicana. Porém, não é esse problema que me interessa aqui. Importa destacar que Kant forja uma definição transcendental da Aufklärung para

\footnotetext{
${ }^{20}$ Cf. Foucault, op. cit., 2008 , p. 34.

${ }^{21}$ Cf. Kant, op. cit., p. 104-105.

${ }^{22}$ Contornando-se, portanto, o obstáculo da autoridade religiosa. Mais do que qualquer outra matéria, a religião, quando não examinada pelo crivo da crítica, tem o poder de cegar os homens, seja submetendo-os docilmente ao diretor de consciência, seja inoculando em seu espírito os excessos do fanatismo.
} 
fundamentar sua injunção de que a realidade política se conforme às exigências da liberdade. A liberdade de pensamento não resulta das revoluções, portanto não é garantida pela desintegração da ordem social. ${ }^{23}$ Mas na agenda política dos governantes na modernidade consta a obrigação de manter um espaço público em que a livre troca de ideias seja respeitada. Esse é o caminho que levará todos os homens ao Esclarecimento.

O artigo de Kant ilustra a formação, na modernidade, de um éthos filosófico da seguinte maneira: ao refletir sobre sua própria época, Kant incorpora sua atividade filosófica ao movimento de saída (Ausgang) da menoridade. Dizendo de outra maneira, a menoridade, que é a incapacidade de fazer uso de sua própria razão sem a direção de outrem, tem como uma de suas condições primeiras o exercício livre da razão no espaço público, que é o uso que Kant mesmo faz de sua filosofia como homem letrado. $\mathrm{O}$ texto de Kant não apenas define as condições de possibilidade da maioridade: ele integra essas condições no momento em que as pensa. Mas isso não é tudo. Se nos contentássemos com o uso público da razão correríamos o risco de reduzir a Aufklärung a um processo puramente intelectual. Por isso, Kant não deixa de assinalar que existem condições "empíricas" para o Esclarecimento, as quais podem ser reduzidas à forma da legalidade e da ordem política. A Aufklärung requer então a existência de um espaço público garantido pelo poder político para produzir seus efeitos emancipatórios sobre a humanidade.

Em que essa série de considerações pode interessar a Foucault? Já me referi à espécie de redobramento, de volta sobre si, de reflexão, que esse texto de Kant realiza, o qual pode ser sentido em diversos níveis. Primeiro, uma retomada da empresa crítica no âmbito da reflexão moral e política. Segundo, o texto de Kant coloca no coração mesmo de sua análise, como vimos, a noção de público a que ele próprio se dirige, ${ }^{24}$ o que leva a uma terceira ponderação, a de que o tema do artigo se confunde com a ação que ele realiza. Vou chamar isso de "coerência performativa". Quarto, o que fica esclarecido no texto é que a questão da Aufklärung é, no fundo, uma genealogia da modernidade como questão. Contudo, vou deixar momentaneamente essas considerações de lado para me ater a um outro tópico: o do governo de si e dos outros.

\footnotetext{
${ }^{23}$ Cf. Kant, op. cit., p. 104-105: Uma revolução poderá talvez realizar a queda do despotismo pessoal ou da opressão ávida de lucros ou de domínios, porém nunca produzirá a verdadeira reforma do modo de pensar. Apenas novos preconceitos, assim como os velhos, servirão como cintas (Leitbande) para conduzir a grande massa destituída de pensamento.

${ }^{24}$ Cf. Foucault, op. cit., 2008, p. 10.
} 
Foucault identifica esse tópico no texto de Kant no ponto em que são examinadas as causas que mantêm os homens na menoridade. Preguiça e covardia (Faulheit und Feigheit) são as responsáveis pelo déficit de autonomia na relação consigo. No entanto, na hora de fazer valer a prescrição do Sapere aude! Kant vai mostrar a importância da ação política. Nos termos de Foucault, a tarefa da Aufklärung será "redistribuir as relações entre governo de si e governo dos outros" ${ }^{25}$ Como concretizar essa redistribuição que deverá resultar no aumento da autonomia? Foucault lembra que aqueles que já atingiram a maioridade não se encontram em condição de promovê-la, a única solução sendo a instituição do espaço em que os homens possam fazer livre uso de sua razão. Ora, nos deparamos aqui com o mesmo problema que examinávamos acima: a autoridade deve ser referida à legalidade e, nesse processo, veremos os homens aptos a constituírem a si mesmos como sujeitos autônomos. ${ }^{26}$

$\mathrm{Na}$ questão da Aufklärung podemos detectar então o tema no qual Foucault está tão interessado nos últimos anos de sua vida: a constituição autônoma de si como sujeito moral. A autoconstituição se efetiva em uma tensão entre política e moral, entre o governo dos outros e o governo de si. Em termos kantianos, sem a limitação da liberdade externa (e Kant não deixa dúvidas de que essa limitação envolve a coerção) não é possível o exercício da liberdade moral. Foucault avança, porém, despedindo-se do sujeito transcendental, na proposta de que a subjetividade resulta desse enfrentamento. É preciso reconhecer, por outro lado, que essa tensão é ela própria integrada na ideia de crítica, o que é assinalado no pertencimento mútuo entre crítica e Aufklärung.

No mesmo período em que inicia o curso de 1983, Foucault prepara um texto em que detalha a natureza desse laço e lança a tese de que a crítica, como Aufklärung, é, sobretudo, uma atitude. Nesse texto, publicado originalmente em 1984 no Foucault reader, organizado por P. Rabinow, está escrito que no pequeno artigo de Kant encontramos o esboço do que poderíamos chamar de "atitude de modernidade". ${ }^{27} \mathrm{Um}$ modo de se entender essa atitude é referindo-se aos desdobramentos já assinalados. Isso porque a Aufklärung é um modo de relação reflexiva com o presente. Mas precisamos esmiuçar um pouco mais essas noções para podermos compreender o projeto de Foucault nesses cursos.

\footnotetext{
${ }^{25}$ Cf. Foucault, op. cit., 2008, p. 32.

${ }^{26}$ E é nessa chave que deveríamos ler a parte do Conflito das faculdades que trata da revolução.

${ }^{27}$ Cf. Foucault, M. Qu'est-ce que les Lumières? In: Dits et écrits IV. Paris: Gallimard, 1994e, p. 568.
} 
A modernidade como atitude inaugura o que Foucault chama de um éthos filosófico. Kant é, indubitavelmente, o primeiro a delinear esse novo éthos uma vez que sua inquirição sobre o Esclarecimento constitui o começo da filosofia moderna. Mas para explicitar essa noção, Foucault se distancia temporariamente do texto de Kant e recorre a Baudelaire, deixando entender que a noção de crítica ganha um novo matiz a partir de suas considerações acerca da modernidade. Como entender essa inflexão?

O texto de Kant, segundo Foucault, permite encarar a modernidade como uma atitude e não como um período histórico. Por atitude ele entende um modo de relação a respeito da atualidade, "uma escolha voluntária que é feita por alguns; enfim uma maneira de pensar e de sentir, uma maneira também de agir e de se conduzir que, ao mesmo tempo, marca uma pertinência e se apresenta como uma tarefa. Um pouco, sem dúvida, como isso que os Gregos chamavam um éthos". ${ }^{28}$ É precisamente aqui que é evocada a figura de Baudelaire, sua sensibilidade e "consciência aguda" da modernidade. Mas não é somente por essas qualidades que Foucault recorre a ele. Mais do que ilustrativa a obra de Baudelaire auxilia Foucault a colocar o problema da crítica em novos termos: aqueles relativos à experiência estética.

Irei me ater apenas aos pontos centrais da leitura que Foucault faz de Baudelaire, estando fora de questão avaliar sua pertinência. $O$ primeiro tópico que é destacado é o do "heroísmo". A atitude de modernidade é caracterizada como uma vontade de "heroificar" o presente, o que significa adotar uma atitude frente ao transitório, ao fugidio, ao contingente que não visa nem a rejeição em favor de uma tradição para sempre perdida nem de resignação e sempre deficiente adaptação, mas uma tentativa de capturar no presente algo de eterno. ${ }^{29} \mathrm{O}$ segundo tópico é o aspecto irônico dessa heroificação, explicado pelo fato de não se tratar em hipótese alguma de uma sacralização do momento que passa "para tentar mantê-lo ou perpetuá-lo". ${ }^{30}$ Não se trata, igualmente, de simplesmente recolhê-lo, impulsionado por uma curiosidade "fugitiva e interessante". O homem de modernidade, exemplificado pela figura de Constantin Guys, não é um flâneur, apesar de aparentemente lhe estar próximo. De fato, Baudelaire atribui a Guys essa curiosidade, manifestada frequentemente na infância e que dela traz a vivacidade e constante inquietação. ${ }^{31}$ Mas,

\footnotetext{
${ }^{28}$ Cf. Foucault, op. cit., 1994e.

${ }^{29}$ Cf. Foucault, op. cit., 1994e, p. 569.

${ }^{30}$ Cf. Foucault, op. cit., 1994e.

${ }^{31}$ Retiro essa passagem do próprio Baudelaire (cf. Baudelaire, C. Sobre a modernidade. Rio de Janeiro: Paz e Terra, 1996, p. 23-24).
} 
diferentemente do flâneur, Guys é um artista que, ao se colocar ao trabalho, transfigura o mundo. Vale a pena reproduzir a passagem em que Foucault explicita essa questão:

Transfiguração que não é anulação do real, mas jogo difícil entre a verdade do real e o exercício da liberdade; as coisas "naturais" aí se tornam "mais do que naturais", as coisas "belas" aí se tornam "mais do que belas" e as coisas singulares aparecem "dotadas de uma vida entusiasta como a alma do autor". Para a atitude de modernidade, o alto valor do presente é indissociável do afinco em imaginar, em imaginá-lo diferentemente do que ele é e em transformá-lo não o destruindo, mas captando-o naquilo que ele é. A modernidade baudelairiana é um exercício onde a extrema atenção ao real é confrontada à prática de uma liberdade que ao mesmo tempo respeita esse real e o viola. ${ }^{32}$

Por fim, o terceiro tópico consiste no ascetismo embutido na atitude de modernidade. Para Foucault, Baudelaire teria compreendido que a modernidade é mais do uma simples relação com o presente, caracterizando também uma relação para consigo mesmo. Não é, portanto, apenas a vontade de mudar o mundo, de transfigurá-lo por meio da arte que constitui o trabalho no qual o artista se empenha. Ele materializa essa transformação em si mesmo: "Ser moderno não é aceitar a si mesmo tal como se é no fluxo de momentos que passam; é tomar-se a si mesmo como objeto de uma elaboração complexa e dura: o que Baudelaire chama, segundo o vocabulário da época, de 'dandismo'." ${ }^{33}$ Se este "si" é o que deve ser constituído a partir de uma ascese, então o homem moderno, como o entende o poeta, não é aquele que realizaria um trabalho hermenêutico sobre si em busca de uma verdade recôndita, mas aquele que "busca inventar a si mesmo. Essa modernidade não libera o homem em seu ser próprio; ela o obriga à tarefa de se elaborar a si mesmo". ${ }^{34}$

Ora, não é difícil reconhecer nesses três tópicos listados o resultado das investigações que Foucault realizou nos últimos anos, orientado pelo objetivo de trazer à luz os contornos gerais de um fenômeno cultural identificável na Antiguidade e que ele denomina de "cuidado de si". No dandismo de Baudelaire encontramos o rosto familiar dos estoicos e dos epicuristas que dispendiam o principal de suas energias em um exercício árduo de transfiguração de si em vista de uma constituição

${ }^{32}$ Cf. Foucault, op. cit., 1994e, p. 570 (grifo meu).

${ }^{33}$ Cf. Foucault, op. cit., 1994e, p. 570.

${ }^{34}$ Cf. Foucault, op. cit., 1994e, p. 571. 
de si mesmo como sujeito moral. Baudelaire permite, portanto, vincular a estilística da existência (a ética estética) à atitude crítica da modernidade, ${ }^{35}$ o que parecia estar muito distante das considerações de Kant. É verdade que, ao identificar a Aufklärung como um processo, Kant abria caminho para uma nova compreensão do moderno: ele não toma o tempo presente em uma relação contínua com o passado e o futuro nem busca encontrar um fio condutor secreto que animaria, em sua interioridade, o movimento das coisas (a leitura de Foucault tende, portanto a desconectar o texto sobre o Esclarecimento da reflexão sobre a História); diferentemente, Kant, ao entender a Aufklärung como saída que é de responsabilidade de cada indivíduo, a compreende, por um lado, como uma diferença no tempo e, por outro, como uma atitude fundamentada na vontade, isto é, como uma decisão. Mas esse gesto (é o que podemos inferir da leitura de Foucault) não inaugura uma forma de subjetividade em que desponta a noção de individualidade. Antes, integra-a em uma concepção de autonomia que delimita o status formal do sujeito moral. Foucault parece entender que falta a Kant uma associação mais estreita entre autonomia e individualidade que será desenvolvida por aqueles autores que adotam uma perspectiva "expressionista" da subjetividade (como aqueles associados ao romantismo alemão). ${ }^{36}$ Foucault necessita,

\footnotetext{
${ }^{35}$ Vale ainda notar que a atitude de modernidade em Baudelaire implica uma retomada do passado, à semelhança do que propõe Foucault com seu retorno à moral antiga. A respeito, Walter Benjamin escreve que é muito importante que o moderno em Baudelaire não apareça sozinho como marca de uma época, e sim como uma energia, graças à qual esta época se apropria imediatamente da Antiguidade. De todas as relações que a modernidade estabelece, a relação que mantém com a Antiguidade éespecial (Benjamin, W. Passagens. Trad. I. Aron. Belo Horizonte: UFMG, 2006, p. 282). Esta referência a Benjamin, por outro lado, obriga-me a fazer observar que, diferentemente de Foucault, ele via na poesia de Baudelaire, especialmente em Asflores do mal, a visão mais aguda da modernidade: Nenhuma das reflexõés estéticas da teoria baudelairiana expõe a modernidade em sua interpenetração com a Antiguidade como ocorre em certos trechos de "As flores do mal". Benjamin, W. Paris no Segundo Império. In:__. Charles Baudelaire. Um lírico no auge do capitalismo. Obras escolhidas III. Trad.J. C. M. Barbosa e H. A. Baptista. São Paulo: Brasiliense, 1989, p. 81. Cf. também artigo de Muricy, K. O poeta da vida moderna. Alea. Rio de Janeiro, vol. IX, n. 1, p. 48-63, janeiro-junho de 2007.

${ }^{36}$ Cf. a respeito artigo de Hinchman, L. Autonomy, individuality and selfdetermination. In: Schmidt, op. cit., p. 488-516. Para uma visão diferente da autonomia e autodeterminação subjetiva em Kant, ver o sugestivo artigo de Diogo Sardinha, Reinventando o sujeito e a crítica. Os antigos, Kant e Baudelaire. In: Gondra, J.; Kohan, W. (Org.). Foucault 80 anos. Belo Horizonte: Autêntica, 2006, p. 247-263.
} 
portanto, de Baudelaire para introduzir na visão da modernidade como atitude crítica o ideal ascético que gemina a liberdade com a prática de si. Contudo, esses não são os únicos benefícios da passagem por Baudelaire. Ela vai subsidiar uma formulação da crítica em novos termos: trata-se de uma "atitude-limite". Mas mesmo aqui ainda é o texto de Kant a grande matriz para Foucault, simplesmente porque a Aufklärung introduz uma tensão entre o que nós somos e o tempo em que vivemos. Como atitude crítica, ela é recuo necessário e ultrapassamento potencial. Vamos examinar o tema um pouco mais detidamente.

O tema do ultrapassamento do limite não é novo na obra de Foucault. Nos anos sessenta, seus vários artigos sobre literatura, assim como seu livro sobre Raymond Roussel, privilegiam uma abordagem da escrita literária na qual desempenham papel fundamental as noções de finitude, transgressão e, claro, limite. A literatura aparecia como um outro espaço (o único, na verdade) em que era possível, na modernidade, a renovação do pensamento (convicção também presente em As palavras e as coisas). No início dos anos 1980 a literatura não recupera esse status. Reaparece a ideia de ultrapassamento dos limites, mas no âmbito, agora, da atividade filosófica. Esta tem a considerável vantagem sobre a primeira: ela permite a comunicação da experiência do ultrapassamento dos limites, ao passo que a literatura conduz ao inefável. ${ }^{37}$ No entanto, em vez de me ater ao problema da comunicação, gostaria de colocar em destaque o jogo entre limite e transgressão e a abertura para uma prática de si que origina subjetividade (ao invés de sermos apenas expostos ao risco da dessubjetivação). O que permanece como ponto importante das análises de Foucault é a crença de que a experiência de novas formas de subjetividade tem como condição de possibilidade a ousadia de ir além dos limites. Uma passagem do texto de 1984 em que Foucault detalha o que entende por éthos filosófico é esclarecedora:

Esse éthos filosófico pode se caracterizar como uma atitude-limite. Não se trata de um comportamento de rejeição (rejet). Devemos escapar à alternativa do fora e do dentro; é preciso estar nas fronteiras. A crítica é exatamente a análise dos limites e a reflexão sobre eles. Mas se a questão kantiana era saber quais limites o conhecimento deve renunciar a ultrapassar, parece-me que a questão crítica, hoje, deve se tornar uma questão positiva: naquilo que nos é dado como universal, necessário, obrigatório, qual é a parte daquilo que é singular, contingente e devido

\footnotetext{
${ }^{37}$ A respeito ver o livro de Machado, R. Foucault, a filosofia e a literatura. Rio de Janeiro: Jorge Zahar Editor, 2000.
} 
às coerções arbitrárias. Trata-se, em suma, de transformar a crítica exercida na forma da limitação necessária em uma crítica prática na forma do ultrapassamento possível. ${ }^{38}$

Isso significa que a crítica que interessa a Foucault não é aquela levada a cabo por uma analítica da verdade - cuja preocupação maior é individuar as "estruturas formais que têm valor universal" -, mas aquela denominada de modo paradoxal "ontologia do presente" - uma "investigação histórica através dos eventos que nos levaram a nos constituir a nós mesmos, a nos reconhecer como sujeitos do que fazemos, pensamos, dizemos". ${ }^{39}$ Esta crítica, claro está, não visa tornar possível uma metafísica; antes, ela é "genealógica em sua finalidade e arqueológica em seu método". Em que sentido?

Arqueológica - e não transcendental - no sentido de que ela não buscará destacar as estruturas universais de todo conhecimento ou de toda ação moral possível; mas em tratar os discursos que articulam o que nós pensamos, dizemos e fazemos como eventos históricos. E esta crítica será genealógica no sentido de que ela não deduzirá da forma do que nós somos o que nos é impossível de fazer ou de conhecer, mas ela retirará da contingência que nos fez ser o que nós somos a possibilidade de não mais ser, fazer ou pensar o que nós somos, fazemos ou pensamos (...) Ela não busca tornar possível a metafísica enfim tornada ciência; ela busca relançar o mais longe e amplamente possível o trabalho indefinido da liberdade. ${ }^{40}$

A "positivação" da crítica, por um lado, consiste na desconstrução, não das verdades universalmente aceitas, mas de seu caráter óbvio e natural. A arqueologia situa na dimensão histórica a "verdade" que os discursos veiculam. Por sua vez, a genealogia desestabiliza a ligação necessária entre o que reconhecemos como verdadeiro em um determinado tempo e nosso modo de ser, fazer e pensar nesse mesmo tempo. A genealogia, liberando-nos dos entraves da essência humana, promove outras formas de constituição de si como sujeito.

Essa conjunção entre arqueologia e genealogia é qualificada então como uma atitude histórico-crítica, termo que Foucault utiliza já em 1978, quando de sua primeira referência pública ao texto de Kant. Tratase de um trabalho sobre nós mesmos que se desdobra em dois domínios:

\footnotetext{
${ }^{38}$ Cf. Foucault, op. cit., 1994e, p. 574 (grifo do autor).

${ }^{39}$ Cf. Foucault, op. cit., 1994e.

${ }^{40}$ Cf. Foucault, op. cit., 1994e.
} 
aquele das investigações históricas e aquele outro no qual colocamos os limites de nós mesmos à prova da realidade e da atualidade, "ao mesmo tempo para apreender os pontos onde a mudança é possível e desejável e para determinar a forma precisa a dar a essa mudança". A exigência de uma "prova da realidade" faz mais uma vez convergir o projeto crítico de Foucault com o de Kant, pois está fora de questão estabelecer um novo programa social ou um outro modo de pensar e fazer que substitua o anterior. Assim como Kant estava ciente dos riscos da revolução (substituir preconceitos velhos por novos), Foucault não deseja impor qualquer projeto global de constituição de si, mas sim fomentar aquelas práticas em que o ganho de autonomia seja evidente. A atitude históricocrítica é, portanto, "provação", "experimentação" e restringe-se a domínios muito precisos, como os que concernem "a nossos modos de ser e de pensar, as relações de autoridade, a relação entre os sexos, a maneira pela qual percebemos a loucura ou a doença". ${ }^{42}$

A opção pela "regionalidade" de suas análises, com o consequente abandono de uma perspectiva totalizante, não condenaria a atitude histórico-crítica ao fracasso, uma vez que perderia de vista o contexto maior em que são exercidas as relações de poder? A negligência para com as estruturas gerais não cobra o preço alto: o enfraquecimento da relevância ou mesmo o déficit de capacidade de intervir na realidade? Ou ainda, o projeto crítico de se deixar determinar por essas estruturas mesmas "das quais não se tem consciência nem domínio"? ${ }^{43}$ Foucault responde a essas dificuldades evocando a generalidade, a sistematicidade, a homogeneidade e o enjeu da crítica.

Seu enjeu pode ser chamado de "paradoxo das relações entre a capacidade e o poder". ${ }^{44}$ A modernidade acena com a promessa de alargamento da liberdade e da autonomia e, no entanto, podemos nela identificar um espantoso crescimento das tecnologias de poder (disciplinar, governamental) e de controle que abalam seriamente seu projeto de emancipação. Mas o trabalho de Foucault não traça as grandes linhas de uma dialética do Esclarecimento: mais pontual, examina as possibilidades de "desconectar o crescimento das capacidades e a intensificação das relações de poder". ${ }^{45}$

\footnotetext{
${ }^{41}$ Cf. Foucault, op. cit., 1994e, p. 574.

${ }^{42}$ Cf. Foucault, op. cit., 1994e, p. 575.

${ }^{43}$ Cf. Foucault, op. cit., 1994e.

${ }^{44}$ Cf. Foucault, op. cit., 1994e.

${ }^{45}$ Cf. Foucault, op. cit., 1994e, p. 576.
} 
A homogeneidade concerne ao que Foucault denomina de "conjuntos práticos" dos quais são destacadas a vertente tecnológica e a vertente estratégica. Por um lado, estão em questão as "formas de racionalidade" que orientam as técnicas políticas; de outro, a liberdade com a qual agem aqueles que se encontram submetidos a esses sistemas práticos, "reagindo ao que os outros fazem, modificando até um certo ponto as regras do jogo". ${ }^{46}$

No que diz respeito à sua sistematicidade, vamos reencontrar aqueles eixos que estruturam a experiência de que falamos acima: o do domínio sobre as coisas (saber), o das relações com os outros (poder), o das relações consigo mesmo (ética), sendo que a crítica interroga as formas de constituição do sujeito em relação com esses domínios em que o ser se deixa pensar.

A generalidade dessas pesquisas, por fim, é garantida pela recorrência, na cultura ocidental ao menos, dos objetos de estudo: a loucura, a relação com a criminalidade e a lei, a sexualidade etc. Mas a generalidade não decorre do caráter metaistórico desses temas e sim do fato de que eles recebem, a cada época, um tratamento particular no qual constituímos a experiência de nós mesmos. Trata-se, em suma, de fazer o estudo dos modos de problematização. ${ }^{47}$

Delineadas as linhas gerais dessa história do presente, dessa ontologia crítica de nós mesmos, resta a Foucault enfatizar que não pretendeu elaborar uma teoria, uma doutrina, nem mesmo "um corpo permanente de saber que se acumula". "É a ideia de um éthos que sai mais uma vez reforçada, assim como a convicção de que a análise histórica abre a possibilidade de ultrapassamento dos limites. O que me interessa destacar, para encerrar esse comentário, é que o trabalho sobre os limites é efetivado simultaneamente sobre os eixos do saber, do poder e da ética. Isso permite encarar o estudo das práticas de governo como um

\footnotetext{
${ }^{46}$ Cf. Foucault, op. cit., 1994e, p. 576.

${ }^{47}$ Cf. Foucault, op. cit., 1994e, p. 577. Para uma exposição mais detalhada da noção de "problematização", ver especialmente a entrevista concedida a F. Ewald em 1984 "Le souci de la vérité" (cf. Foucault, op. cit., 1994f, p. 668-678): "Problematização não quer dizer representação de um objeto preexistente, nem também criação pelo discurso de um objeto que não existe. É o conjunto de práticas discursivas ou não discursivas que faz entrar algo no jogo do verdadeiro e do falso e o constitui como objeto para o pensamento (que seja a forma da reflexão moral, do conhecimento científico, da análise política, etc.)", p. 670.

${ }^{48}$ Cf. Foucault, op. cit., 1994e, p. 577.
} 
momento decisivo da ontologia do presente. Com efeito, a ideia de governo não pode ser dissociada da de relação. Seja o governo dos outros, seja o governo de si, o que parece essencial é que estabelecemos nessa forma de atividade uma relação com outrem ou com nós mesmos da qual resulta uma forma de subjetividade. Se entendermos o problema do governo nessa chave, que associações podemos fazer com a noção de limite e com o projeto crítico? Ora, tanto no âmbito da política (o governo dos outros) quanto no âmbito da ética (o governo de si) o exercício do poder se constitui como a ativação de um conjunto de estratégias, de um aparato que envolve mais ou menos intensamente o uso da força: no primeiro caso, aquela que exercemos contra/sobre um outro; no segundo, aquela que exercemos sobre nós mesmos com vistas à produção de um si. Convém notar que a força não é sinônimo de poder (assim como não o é a violência), mas seu instrumento. ${ }^{49}$ Diferentemente da força e da violência, o poder não se exerce diretamente sobre os sujeitos. Como governo, o poder é antes direção das condutas, isto é, um modo de agir sobre a ação:

Ele é um conjunto de ações sobre ações possíveis: ele opera sobre o campo de possibilidade onde vem se inscrever o comportamento dos sujeitos agentes; ele incita, ele induz, ele desvia, ele facilita ou torna mais difícil, ele alarga ou limita, ele torna mais ou menos provável; no limite, ele constrange ou impede absolutamente; mas ele é sempre uma maneira de agir sobre um ou sobre sujeitos agentes, e isso enquanto agem ou são suscetíveis de agir. Uma ação sobre ações. ${ }^{50}$

Essa vigorosa dessubstancialização do poder tem como contrapartida a dessubstancialização do sujeito, o qual perde sua anterioridade com relação ao poder, deixa de ser seu anteparo, para ser compreendido como seu resultado. Isso quer dizer que a subjetividade deve ser identificada com a fronteira, com o limite que separa o poder que vem de fora e a resistência que ele encontra. ${ }^{51}$ Feitas essas considerações,

\footnotetext{
${ }^{49}$ Para a distinção entre poder e violência, ver o texto que Foucault escreveu (e que foi incluído na segunda edição como anexo) para o livro de H. Dreyfus e P. Rabinow Michel Foucault. Beyond structuralism and hermeneutics. Chicago: The University of Chicago Press, 1983, p. 208-226. Esse texto foi incluído em Foucault, op. cit., 1994e, p. 222-243.

${ }^{50} \mathrm{Cf}$. Foucault, M. Le sujet et le pouvoir. In: . Dits et écrits IV. Paris: Gallimard, 1994d, p. 237.

${ }^{51}$ Para essa ideia do sujeito, ver o texto de D. Sardinha citado acima e também G. Deleuze, Le plissement ou le dedans de la pensée. In: Foucault. Paris: Les Éditions de Minuit, 1986, p. 101-130.
} 
acredito que fique mais fácil entender como a investigação acerca do governo de si e dos outros está inserida no projeto crítico. Se o tema geral das pesquisas de Foucault sempre foi o sujeito, ${ }^{52}$ o estudo histórico dos seus modos de constituição, vale dizer, envolve necessariamente a análise das relações que estabelecemos entre o "dentro e o fora". Estes estudos não tomam a fronteira, os limites, como positividades, mas como limiares que podem ser modificados, inflexionados por um "trabalho paciente que dê forma à impaciência da liberdade". ${ }^{33}$ A ontologia histórica de nós mesmos tem de trazer à luz os enfrentamentos singulares (pois se articulam diferentemente ao longo da história) entre si e entre outros. Mais precisamente, trata-se de esclarecer que a constituição de um "si" não se concretiza sem a presença de um "outro" em uma experiência na qual estão articulados saber e poder.

Para encerrar essa breve exposição, gostaria de mais uma vez observar que é nessa junção entre poder e saber, presente já no texto de Kant, que Foucault pode alojar seu próprio trabalho intelectual. Tanto a arqueologia do saber quanto a genealogia do poder dão corpo ao éthos filosófico de Foucault em sua constante interrrogação sobre o que somos no tempo presente. Essa interrogação, a exemplo da empresa kantiana, tem como uma de suas questões maiores aquela da autonomia, que Foucault entende da seguinte maneira: assim como Kant está preocupado em identificar os mecanismos pelos quais os homens podem desenvolver sua autonomia, as investigações arqueogenealógicas exploram as possibilidades de que dispomos para nos constituir a nós mesmos como sujeitos livres.

Essas investigações não poderiam tomar o sujeito em sua positividade como tema de investigação sem promover sua substancialização. A via percorrida por Foucault vai encontrar o sujeito nos lugares em que ele vem a ser formado pelos mais diversos dispositivos de saber e poder. Mas na ocasião em que descreve seu próprio trabalho como uma "ontologia do presente" o que está em questão são as formas pelas quais o sujeito pode constituir a si mesmo. Foucault observa, porém, que a autossubjetivação não se efetiva em um vazio social ou político. Pelo contrário, constituímos a nós mesmos

\footnotetext{
${ }^{52}$ Cf. Foucault, op. cit., 1994e, p. 223.

${ }^{53}$ Cf. Foucault, op. cit., 1994e, p. 578.
} 
como sujeitos estabelecendo relações intersubjetivas inseridas em jogos de poder e em redes de saber. Nos trabalhos finais de Foucault, contudo, o eixo privilegiado é o da subjetividade e é a partir dele que se estruturam os eixos do poder e do saber.

Essa nova disposição de seu trabalho intelectual coordena suas investigações acerca da prática de si na Antiguidade grega e romana, centrando-se, nos últimos cursos, no problema do governo de si e dos outros. Mas em que medida o trabalho final de Foucault nos ajuda a compreender o sentido de uma "ontologia do presente"? A pergunta ganha mais força se lembrarmos que o termo é utilizado na abertura do curso de 1983 (o qual está fortemente vinculado ao de 1984).

O estudo das práticas de si (envolvendo aí as diversas modalidades de exercício do poder sobre o outro e sobre si mesmo) integra uma ontologia do presente na medida em que mostram possibilidades de autoconstituição de si distintas daquelas que conhecemos no presente. Mas não se trata de um receituário filosófico: trata-se, antes, de abalar a universalidade daquilo que é reconhecido como óbvio no tempo atual como estratégia para promover outras formas de subjetividade. $\mathrm{Na}$ verdade, esse é o trabalho ético que está reservado a todos nós e que Foucault certa vez formulou de maneira muito sugestiva e reveladora: o que está em jogo é um "trabalho paciente que dê forma à impaciência da liberdade". ${ }^{54}$ Essa declaração é reveladora porque deixa transparecer uma tese de fundo que orienta toda a reflexão de Foucault: a de uma indeterminação radical de nossa existência. Mas se essa indeterminação pode ser entendida negativamente como a necessidade de ultrapassamento de limites, ela também pode ser tomada positivamente como o trabalho constante de dar forma à própria existência. Esse trabalho, quero crer, não pode ser um ponto de partida absolutamente novo. À sua disposição se encontra o acervo de nossas experiências (mas valeria tomar este termo no sentido que lhe dá Foucault, isto é, destacando seus três elementos: 1) "as formas de um saber possível"; 2) "as matrizes normativas de comportamento para os indivíduos"; 3) "os modos de existência virtuais para sujeitos possíveis" "55 que, certamente, não determinam esse trabalho, mas o informam. Eis, a meu ver, um dos sentidos de uma "ontologia do presente".

${ }^{54}$ Cf. Foucault, op. cit., 1994f, p. 578.

${ }^{55}$ Cf. Foucault, op. cit., 2008, p. 4-5. 


\section{Referências}

BAUDELAIRE, C. Sobre a modernidade. Teixeira Coelho (Org.). Rio de Janeiro: Paz e Terra, 1996.

BENJAMIN, W. Passagens. Trad. I. Aron e C. P. Barreto Mourão. Belo Horizonte: UFMG, 2006.

. Charles Baudelaire. Um lírico no auge do capitalismo. Obras escolhidas III. Trad. J. C. M. Barbosa e H. A. Baptista. São Paulo: Brasiliense, 1989.

DÁVILA, J. Una exégesis del texto “¿Qué es la Ilustración?” como testamento intelectual de M. Foucault. In: Literatura y conocimiento. Michel Foucault. Caracas, Ediciones de la ULA, 1999, p. 1-11. Acessível em: <http://www.saber.ula.ve/ bitstream/123456789/15900/1/davila-ilustracion.pdf>

DELEUZE, G. Foucault. Paris: Les Éditions de Minuit, 1986.

DREYFUS, H.; RABINOW, P. Michel Foucault. Beyond structuralism and hermeneutics. Chicago: The University of Chicago Press, 1983.

FOUCAULT, M. Entretien avec Michel Foucault. In: . Dits et écrits II. Paris Gallimard, 1994a, p. 157-174.

. L'archéologie du savoir. Paris: Gallimard, 1969.

. La vie: l'expérience et la science. In: . Dits et écrits IV. Paris: Gallimard, 1994b, p. 763-776

. Le courage de la vérité. Le gouvernement de soi et des autres II. Cours au Collège de France 1984. Paris: Gallimard/ Seuil, 2009.

Le gouvernement de soi et des autres. Cours au Collège de France 1982-1983. Paris: Gallimard/Seuil, 2008.

. Le souci de la vérité. In: p. 668-678.

. Le sujet et le pouvoir. In: Dits et écrits IV. Paris: Gallimard, 1994c, p. 222-43.

. Qu'est-ce que les Lumières? In: 1994e, p. 562-84.

. Qui êtes-vous, Professeur Foucault? In: Dits et écrits IV. Paris: Gallimard, Gallimard, 1994f, p. 601-620.

HAN, B. L'ontologie manquée de Michel Foucault. Grenoble: Millon, 1998.

HUSSERL, E. La crise des sciences européennes et la phénoménologie transcendentale. Trad. G. Granel. Paris: Gallimard, 1976.

KANT, I. Resposta à pergunta: “que é Esclarecimento?” (Aufklärung). Trad. Floriano de S. Fernandes. In: Immanuel Kant. Textos seletos. Petrópolis: Vozes, 1985, p. $100-117$.

LEBRUN, G. Note sur la phénoménologie dans "Les mots el les choses". In: .Canguilhem, G. (Org.). Michel Foucault philosophe. Paris: Seuil, 1989, p. 33-53. 
MACHADO, R. Foucault, a filosofia e a literatura. Rio de Janeiro: Jorge Zahar, 2000.

MURICY, K. O Poeta da vida moderna. Alea. Rio de Janeiro, v. IX, n. 1, p. 48-63, janeiro-junho de 2007.

SARDINHA, D. Reinventando o sujeito e a crítica. Os antigos, Kant e Baudelaire. In: Gondra, J.; Kohan, W. (Org.). Foucault 80 anos. Belo Horizonte: Autêntica, 2006, p. 247-263.

SCHIMDT,J. (Org.). What is Enlightenment? Eighteenth-Century answers and TwentiethCentury questions. Berkeley: University of Califórnia Press, 1996.

TORRES FILHO, R. R. Respondendo à pergunta: quem é a Ilustração?. In:

Ensaios defilosofia ilustrada. São Paulo: Brasiliense, 1987, p. 84-101. 